This item was submitted to Loughborough's Research Repository by the author.

Items in Figshare are protected by copyright, with all rights reserved, unless otherwise indicated.

\title{
Entry and exit as embodied career choice in professional sport
}

PLEASE CITE THE PUBLISHED VERSION

http://dx.doi.org/10.1016/j.jvb.2015.08.003

\section{PUBLISHER}

(c) Elsevier

VERSION

AM (Accepted Manuscript)

\section{PUBLISHER STATEMENT}

This work is made available according to the conditions of the Creative Commons Attribution-NonCommercialNoDerivatives 4.0 International (CC BY-NC-ND 4.0) licence. Full details of this licence are available at: https://creativecommons.org/licenses/by-nc-nd/4.0/

\section{LICENCE}

CC BY-NC-ND 4.0

\section{REPOSITORY RECORD}

Coupland, Christine. 2015. "Entry and Exit as Embodied Career Choice in Professional Sport". Loughborough University. https://hdl.handle.net/2134/18972. 


\title{
Coupland, C. (2015) Entry and exit as embodied career choice in professional sport. Journal of Vocational Behavior: on line first 10.1016/j.jvb.2015.08.003
}

\begin{abstract}
The concept of an embodied career draws attention to the individual, corporally, socially, culturally and institutionally located in relationship with work. Career theories have tended to focus on psychological and social variables and measurements that narrow understanding of contexts and agency. It is thus timely to consider a more holistic approach to understanding contemporary careers as embodied processes. The paper works on three levels; first as an empirical illustration of professional sports careers as short-term careers, second as an application of Bourdieu's habitus to understand the relationship between social fields and accounts of career choice and, third in order to draw parallels with the embodied nature of work in a more general sense. Utilising empirical material from a study of elite UK professional rugby players, it is argued that understanding an embodied-career resonates with present concerns regarding career patterns of short-term contracts, which require the individual to be committed, flexible and adaptable, be prepared for exit, and yet remain immersed and dedicated to the current sphere of employment. It is proposed that this kind of immersion requires alternatives to be, temporarily at least, silenced and in this context renders the accrual of bodily capital as fit, but only temporarily fit for purpose.
\end{abstract}

Key words: Bourdieu; career; career choice; embodiment; habitus; rugby league; professional sport

\section{Introduction}

In keeping with recent calls for new developments in career theory (Chudzikowski and Mayrhofer, 2011) and a plea to move beyond variable and measurement driven career research (Van Maanen, 2015) the paper contributes to a better understanding of career 
choices. Career theorists who are interested in the individual in intersection with the institution of work tend to concentrate, in the main, on traditional work places. In contrast, this is a study of a professional sports organization - or more specifically the players who work for this organization. Empirical material from interviews with players who are performing at an elite level in a professional UK, Rugby League Football Club, hereafter given the pseudonym Northern Knights, is drawn upon. By deciding to discuss careers of sports professionals, it firmly locates interest in the notion of sport as work. It is argued that the context of sport offers an unusual viewpoint from which to observe how norms of a career are produced.

The theoretical background to the study draws on Bourdieu's theory of practice (Bourdieu, 1977; 1990). Bourdieu's ideas facilitate an understanding of career as set within an intersection of 'societal history and individual biography' (Grandjean, 1981, p. 1057) and thus provides a useful framework to better understand careers (Chudzikowski and Mayrhofer, 2011).

It is not the intention of the paper to provide a comprehensive account of Bourdieu's concepts, (see Ozbilgin and Tatli (2005) for an accessible summary), however it is argued that the application of the concept of habitus is of particular interest to career theorists (Vilhjálmsdóttir and Arnkelsson, 2013) as it provides a perspective which looks at career choice as both embodied and institutionalised. In basic terms, habitus provides strategies for individuals to act in social interactive spaces. While the spaces provide structuring conditions, the concept of habitus allows room for individual improvisation. Furthermore, choices, or accounts of choices, are selected from a range of possibilities whereby individuals' social histories enable them to perceive what is possible. Hence, career choices and their justifications are veiled, framed or couched within what is perceived to be appropriate to say. 
This is of interest to career scholars as an increased awareness of social and individual aspects of career choice enables a better understanding of structuring social forces.

In the remainder of the paper recent developments in career theory in sport and work contexts will be briefly examined, followed by details of the empirical context and study. The purpose of the paper is to illustrate some ordinarily invisible logics of embodied, temporary, careers through a study of professional athletes' accounts. This is achieved by utilising Bourdieu's theoretical concepts and applying them to accounts of career choice and hence demonstrating their wider applicability to career theorists. Career choice is demonstrated to be a sociallylocated phenomenon that is constructed from the resources available in a given context, from within a habitus crafted from past experience. Concerns with legitimacy or coherence feature in post-hoc choice rationalizations and predicted choice is constrained where a silent future self is deemed as unimaginable.

\section{Career theories in professional sport contexts}

While it is not the remit of the paper to review the vast amount of literature produced from within the sociology of sport, some key findings which are of particular significance to the study of careers more broadly are relevant. Many athletes begin competitive sport at a very early age, thus involvement in sport is reinforced by significant others. When associated with personal success this leads to a strong self-identification of the self as athlete (Baillie, 1993, p. 400). It has been suggested that the level of dedication and commitment required thereafter may result in a premature narrowing of focus with academic and social goals being subordinated to athletic achievement, hence a potential lack of consideration of alternative career options (Blann, 1985) and limits to opportunities for the development of alternative selves (Coakley, 1992; Lavallee, 2005). From career development studies Gati (1986) has argued that the career development decision making model works on the understanding that the individual sequentially eliminates occupational alternatives to arrive at career decisions at 
different stages of their career. It can be argued, therefore, that athletes' focus on the promise of a professional sporting career may have resulted in a premature elimination of other alternatives. Furthermore, studies have demonstrated that athletes identify with and acquiesce towards managerially driven precepts (McGillivray, Fearn and McIntosh, 2005) in their drive to be picked to play. Wacquant has described this as a 'coerced affection' for the game (Wacquant, 1995b, p. 521) with a lack of awareness of the operation of a dominant logic that precludes all alternatives and thus constructs the natural order of things. What is meant by the 'natural order of things' is that, over time, decisions around what is appropriate in certain social spaces, including workplaces, become sedimented, hence they have been forgotten as part of a decision process and are taken for granted as 'the way things are'. Thus, subsequent and ongoing investment in the self-as-athlete reinforces a lack of consideration of alternatives beyond the playing career. This explains to a large extent the lack of take-up of post-playing career planning (Lavallee, 2005) by some professional sports people.

In professional sport there is an inevitable end to playing at a relatively early age (around mid-thirties, or earlier), whether it occurs suddenly through injury or slowly through deterioration in motivation or skills over time, it is a transition which cannot be avoided. Scholars have argued that these are difficult transitions due to the intense identification of an athlete with their sport 'who am I if I can no longer compete' (Day, Gordon and Fink, 2012, p. 420). Players are subsequently labelled as 'retired' or veterans' in terms of their sporting careers. Thus, it is argued that there is evidently room for potential integration around the study of difficult career transitions and their identity implications in both work and sports contexts.

Much research into career choices of sports people are post-playing career explorations. Wainwright and Turner's (2006) study of ageing ballet dancers, for example, was of dancers who were coming to the end of their careers and where increasing age provided the epiphany 
that encouraged dancers to reflect on their embodied habitus and career. It is suggested that physical and psychological immersion would have already been in decline for these participants, hence the kind of immersion that renders norms and practices as taken for granted or invisible would be reducing in order for the individual to begin to contemplate an alternative career path. It is timely, appropriate and unusual, therefore to interview young, currently successful and hence fully immersed, sports people who are at the height of their playing careers (playing for one of the teams in the top league in the UK); in order for them to account for their career 'choice' and to imagine/predict future non-playing selves. The study provides an example of this.

Furthermore, much of the sport career research, which looks at transitions beyond sport, relies upon interviews with past players who have experienced job loss and have coped with repeated employer change (e.g. Roderick, 2014). While these accounts are useful to understand coping mechanisms, post-play, they do not illustrate how the prevailing dominant logic holds a player 'in thrall' while rising through their playing career. It is to this omission that the paper contributes.

\section{Recent developments in work career theory}

It is well understood that having a career as a professional sports person has a large degree of uncertainty about it. This has much in common with contemporary work career experiences of a number of people. However, there is one certainty to this career, that is, it will end rather prematurely in comparison to other careers (in terms of life span) and will therefore require the individual to re-craft a new career and re-construct a version of their selves in order to move forward with their working lives. One role of career theorists is to explore and explain how we make sense of life transitions especially within the messy contexts of non-linear, discontinuous, careers (Sullivan, 1999), causing the non-traditional career (however defined) to be increasingly the focus of empirical research. It is suggested that basic principles around 
work careers apply to professional sports' careers in several ways; differences in career performances lead to differing rewards, rewards are not necessarily material and the ultimate reward is prestige or a satisfactory sense of self (Goldschmidt, 1990, p. 109).

There has been substantial empirical work over the years in the name of career-research, all of which has been driven by particular theoretical and disciplinary perspectives which deem appropriate certain methods and findings. In the main, in contemporary work contexts, the current most influential career theories have largely assumed positions of choice for the individual around career change (see for example Boundaryless and Protean career theories (Arthur and Rousseau, 1996; DeFillipi and Arthur, 1996; Hall, 1996). Hence insights into the social nature of career choice are invaluable.

Work careers today are also characterised by fragmentation and a need to transition, which leads individuals to have to manage their careers by being prepared to be flexible. Hall's (1996; 2004) protean career theory describes a career as managed by the individual according to their own values. When it was first conceived it was positioned as different from a 'traditional' career where control was firmly located in the individual who saw success in psychological terms rather than through principally objective signs such as salary, position and status. While this theory remains influential there is scope for it to be developed in order to take more consideration of social and institutional variables which are at play in career choices.

Boundaryless careers were, initially, broadly described as the opposite of organizational careers and indicated a progressive approach to the study of careers. In the vast amount of research generated since the evolution of 'boundaryless careers' as an explanatory concept (see Sullivan and Arthur, 2006 and Inkson, Gunz, Ganesh and Roper, 2012, for a reexamination of the concept), the notion of what a boundary is seems to expand alongside the 
number of studies of it. Thus, the boundaryless career has evolved in its meaning from one that describes a changing relationship with the employing organization in the early days of its use to an evocation of potential freedom (Cohen and Mallon, 1999), which has generated much debate. Perceptions of boundaries over which one makes a transition remain little understood, hence Pringle and Mallon's (2003) call to attend to individuals' changing perceptions of boundaries. It is proposed that by looking at professional sports contexts as necessarily bounded through body-work and thus body-decline, the notion of choice is constrained, but these theories offer some explanation of boundaries as perceived by the boundary crosser.

The development of linear stage models of career development such as Super (1990) were originally based on psychological perspectives. More recently Savickas (2006) has integrated the stage theory approach to include environmental and social variables. In his development of the theory of career construction, instead of measuring personality traits as realist concepts, personality scores are replaced with a focus on accounts or stories of career experiences and how individuals use vocational identities to adapt to a sequence of job changes while remaining coherent to themselves. It is from within this school of thought that the study emanates.

In summary, scholars who have an interest in careers hail from many and varied disciplines which has led, over time, to quite entrenched positions being taken as to what constitutes useful or even 'good' research. Chudzikowski and Mayrhofer (2011) recently summarised this issue as hindering a better understanding of what matters in career research. Bourdieu's theory of practice was described as an exemplar by these scholars of an overarching theory that may provide an opportunity for developing career theory. 
To reiterate, the intention of the paper is to demonstrate how utilising Bourdieu's concepts can make ordinarily invisible, career-relevant, logics visible and thus demonstrate their wider applicability to career theorists. The embodied nature of these logics is one issue that is examined. This is accomplished by attending to the research task of a close study of careertalk as constructed by particular people in a particular place (Van Maanen, 2015).

\section{Material and methods}

\subsection{The context}

The context is a study of the 'Northern Knights'. Previous studies of rugby have described it as a 'sport of violence' (Pringle, 2001, p. 425). Thus, it is a full body sport with a high premium placed on physical force as well as skill, which enables some comparison with football in the US. At the time of the study Northern Knights were playing in the Super League, the top division for rugby league in the UK. The national context may be an important factor in career trajectories of professional sports people. That said, highly publicised incidences of attempted suicide, gambling, relationship breakdown and excessive alcohol problems feature in this national context around this sport's ex-players, among others, which suggests that there are ongoing transitional issues that require academic attention. The specific context of the study does not enable a universalising claim to the research, different national contexts and different sport contexts give radically different meanings to a future career beyond playing. However, what will resonate with readers transnationally is the shared and well-understood expectation of an individual's total immersion in sport, and more increasingly in work contexts, which appears to preclude envisioning future selves, despite offers (albeit limited) of career advice for beyond playing.

In contrast to other professional sports, rugby players have a fairly recent history of playing at semi-professional level. These athletes are not in receipt of high salaries on a global stage; 
their elite status is situated quite locally within particular towns and cities of working class communities in the UK. Historical events still impact on the way the game is played today. A divide between rugby league and rugby union in the UK came about where (predominantly Northern) players were given 'boot money' as they missed paid work in order to play. This caused a break away from the traditional amateur status of the game and two different sets of rules of play emerged. Although both rugby union and rugby league are professional sports now, the demarcation lines still exist today roughly along a north/south divide in the UK (with exceptions). This has implications for the size of any club's income, taken from attendance at the game, known as the 'gate', and the potential of being a self-funded organization, (arguably there is more disposable income in the south). There is a class issue here too which emanates from the historical context that sees rugby league being played initially in heavy industrial working class areas, e.g. coal mining areas or the docklands, which have now declined. The predominant employment is these post-industrial cities is working in the service sector.

Income generated through professional rugby is quite low as it is subject to wage-capping which means that players' salaries are reduced. Thus, this is a professional sport which is constrained financially and is supported through the altruism of local benefactors and the loyalty of the fans. The players included a small number of overseas 'stars', generally from Australia, Samoa and New Zealand, who were attracted by the relatively high salaries. Local men from the city, who had been developed through the organization's academy system, were employed on much lower salaries. The academy system began as early as 16 years of age, although the coaches paid visits to local senior schools (ages 11-16) in order to identify any potential future talent as part of their recruitment work. Club contracts for first team players are typically for three years, but these may be extended for one year at a time. The longest tenure at the time of the study was 4 years; the longest contract was for 3 years. The 
contract can be ended by the club at any time based on performance issues on or off the pitch. There is a period towards the end of each season when new players are sought but much of this activity is kept from public view.

Playing careers are short, although first team members as young as 16 are not unheard of. At the level of Super League it would be rare to find a player still playing regularly beyond his mid-thirties. A typical career trajectory would be joining a club at a young age and progressing through the ranks to become a senior player. Throughout this time being selected to play is dependent upon ability and is regarded as a marker of value to the club. Alternative routes in the career could include being offered a contract at another club which would be subject to similar patterns of weekly selection. From the club’s perspective new players may be sought to fill perceived gaps in skills that the team require, which would lead to dropping some players and buying in new players.

\subsection{Empirical material}

The empirical material is drawn from a larger ethnographic study of the club (Coupland, 2014; Brown and Coupland, 2015). The study took place over 14 months, from the beginning of April 2011 to the end of May 2012. Although the extracts which are reproduced in the paper were taken from verbatim transcriptions of interviews with the first team players, understanding and subsequent analysis has been informed by an ethnographic perspective. Specifically for the paper, 23 players were interviewed from a first team squad of 23; three of these were group interviews, each of the interviews typically lasting approximately one hour. The players' relaxed relationship with the researcher meant that on several occasions friends of the player being interviewed - who happened to be passing - pulled-up chairs and joined in the conversation, apparently curious to join the discussion. It may be that one consequence of this was that the accounts given in these interactions were as much for themselves and one 
another as for the interviewer. For a study which is looking at accepted practices and logics of a career, conjoined conversations can help to provide illustrations of normative understanding in this community. Age profiles of the players and indicative questions used in interviews with the players are in the Appendix.

Data collection took place in various forms throughout the period of study. In addition to carrying out more formal interviews, the researcher attended corporate events, training sessions, player-fan committee meetings and social events for the players' families. The researcher would also spend on average one day a week at the club, taking temporary residence in the football manager's office (where other trainers and players spent some time each day). Some matches and off-field events during the playing season were also attended. The formal interviews with members of the club comprised 47 members across a range of roles from Director, coaches and other supporting staff to players at various stages in their playing careers. In ethnographic 'style', in addition, much of the time was spent 'hanging around' (van Maanen, 2011) observing and noting the mundane, ritualistic and unusual occurrences of the organization. Training sessions were held by the football staff for the players each morning between 9.00am and 11.00am most days, followed by lunch and other training activities. The researcher attended some of these and took up a position on the side lines at some of the on-the-pitch training sessions waiting for individual meetings or interviews. By deliberately arriving 'early' the researcher could legitimately be seen to be doing 'nothing' while observing and listening to the coach /football staff /player interactions on the field of play. In addition to recorded formal interviews, notes were taken of observations and events throughout the course of the day and at the end of each day.

\section{Analysis}

It is proposed that Bourdieu's concepts of field, habitus and capital are relevant as theoretical schema in terms of explaining broader relationships between the embodied self and the 
organized individual (Wacquant, 1995a; Wainwright and Turner, 2006). The concepts are linked where practice is the result of various habitual schemas and dispositions combined with resources (capital) being activated by social conditions (field) which they in turn reproduce and modify (Crossley, 2001). According to Bourdieu behaviour is not determined by this system, but it provides a practical sense that inclines us towards one way of being rather than another. Thus, as choice is central to understanding vocational guidance, this theory enables us to consider more closely the social aspect of 'choosing a career' as accounted for in a specific work context.

A detailed study of the career talk of members of one professional sports organization has enabled some analysis of the capacity of elite professional players to consider their career pathways - the development of future capital (McGillivray et al., 2005). The analytical process began with a search for how career decisions were constructed in the interviews. All of the players, for example, provided some explanation for entry to professional rugby league. A selection of extracts from these accounts in the data is discussed in the first section of analysis entitled, habitus and sub-sectioned 'beginnings' and 'endings'. One critique of relying on spoken data to demonstrate habitus is that what is taken for granted may not be spoken about. This is a reasonable charge; however, the researcher's ethnographic immersion in the field has enabled a greater awareness of what was accepted as 'normal' and that knowledge has informed the analytical perspective. The second focus of analysis was to explore how the players talked about the forthcoming end of their playing careers. This section is called post-sport careers, which led from a search of the data for instances of talk about how they were preparing, or planning to prepare, for a post-playing career.

The players accounts of their career choices and potential future choices is of interest. How the account is structured is also considered in the analytical process together with the prevailing question 'why this, why now'. These analytical strategies have proved fruitful in 
making ordinarily invisible logics visible. That is, they allow the emergence of resources, or capitals to use Bourdieu's term, that the participants draw upon to provide a plausible and legitimate account.

\subsection{Habitus}

Habitus is a concept which explains the dispositions that influence individuals in their practices. Other studies of career choice have shown the influence of habitus on career decision making (Guichard, 2009; Vilhjálmsdóttir and Arnkelsson, 2013). The participants’ habitus emanates from their previous experiences played out currently in the context of professional sport. Thus, their life histories as UK, Northern, working class, in a postindustrial working environment are brought to bear on their current status as (locally at least) elite professional sports people, that is, 'local lads, done well'. How they account for this is presented below in their post-hoc descriptions of how they became rugby players.

\subsection{Beginnings}

The words of the participants illustrated in the extracts below, are taken from the rugby players’ stories of their experiences:

P6 Yeah, my, my dad played for (Club name), he won the Challenge Cup in seventy seven, and ever since a kid I've always played, started rugby at three because my brother, all the brothers played so, like trained with his team and always, that's all I've ever done.

P9 Yeah, well I played since I was seven, like I got picked up by a friend of my dad's because he ran a team for his two sons and I was always bigger than the other kids at a young age so he said oh we could use, we could use like a lad of your size so do you fancy going, coming down? And that was when I was seven, just played ever since.

PL It's all I know

PH It's in my blood 
It may be surprising to see that the participants' articulations of agency are around dispositions to be unable to do otherwise. That is not to suggest that deliberate decisionmaking did not occur, it may have, we cannot access decision making processes from the past. What we have is a particular view presented while being an elite sport professional. It is thus argued that these accounts of beginnings are constructed as the natural order of things, through claims like 'always wanted to be', or family influence being described as important. This resonates with Wacquant's (1995a) study of boxing where his participants too talked about their work as 'a kind of possession', effecting a lack of strategic agency in their accounting. Other studies of working class young men have recalled choices of jobs made in this way (e.g. Artaraz, 2006; Colley, 2003; Willis, 1977). Hence, it is proposed that the participants' practices combine various habitual schemas, which include earlier socialisation experiences, in this work context. With regard to the embodied practices of these working men, other scholars have suggested that working class men's orientations to work are structured within a habitus of poor education (Nixon, 2006; 2009), which may lead to the development and utilisation of the body as a form of natural working capital. This is not without cost, as seen in the extract below where one player alludes to the pain associated with using the body for sport as 'normal'.

PF It's probably been about since I was sixteen or seventeen I haven't woken up feeling fully, fully fine...so it's kind of part of the game' ....you win one week you lose the next you're crap so ...big part of the game is people that can handle mental ups and downs is probably what keeps you in the game’

Further, this is not to suggest a mind-body split, rather it is argued that an embodied career also embraces psychological processes which are required in order to be 'fit' for this work. Attention is paid during the career to keeping the body fit for work; the following extract is from a 22 year old player. 
PL As I have got older I realise I need to take care of my body, I've got the nutritionists phone number on my mobile.'

Thus, career choice and preference appears to be constructed here as utilisation and development of bodily skill or attributes, following family traditions, embodied-capital, and almost accidental. Entry to this field may be retrospectively constructed as almost accidental and beyond the control of the player (compelled to do it) but the natural capital resources are then honed in order to produce value in terms of income and recognition on the pitch for the benefit of the individual, the club and the industry more broadly. Of interest here is what discursive or narrative resources are drawn on to account for their career choice, albeit retrospectively and why that might be? This is returned to in the discussion.

\subsection{And endings}

Studies of sporting careers focus, perhaps understandably, mostly on physical capital. Although this does not suggest that it is a mindless engagement with sport - intelligence, craft and psychological strength are required for the more skilled rugby players. This is in keeping with Wacquant's (1995b, p. 503) boxers 'boxing is a highly skilled activity that requires mastery of a complex and multi-layered corpus of knowledge'. The embodied aspect of the career is demonstrated through the players' attention to how they control their lives. The extract below is from a player aged 26 .

PG When I was younger I just wanted to have fun and enjoy life now I only drink ...if I had earned it from a fan's point of view.

So, self-regulation occurs as a response to the fans expectations of appropriate behaviour. But despite all endeavours there comes a point when it is time to leave the profession. In the following extract the player, currently aged 20, talks about a future view of his career. 
P10 You will only have your contract extended if you can play well, it depends on injury and ability, you can move down the ranks until you are playing for a team you are not particularly proud of then your body is telling you it is time to go.

Embodied careers, therefore include feedback from the body around appropriate levels of ability, or physical capital, which will enable the continuance of the career. The notion of embodied capital fits with Bourdieu's concept of habitus which illuminates a circular process whereby practices incorporated into the body are regenerated through embodied work (Crossley 2001). In sports, understandably, there is a focus on embodied competence (Wacquant, 1995a). This understanding is demonstrated through the participants' extracts below where they align their future plans with body performances:

PD Yeah, well I'll be thirty one in five years' time and like to think I've still got another five years in me, you know, if the body's good and, you know, opportunities still around, so, yeah, hopefully, hopefully still running around somewhere or, you know, playing somewhere or even family, have family of my own and, yeah, not sure in, in terms of footie, yeah, hopefully still running around, yeah.

PH I'd like to be still at [club] playing super league, that's, that's like my priority and obviously by like five years’ time I'd love to be playing for my country or played for my country by then, injury free, hopefully.

The final, following, extract in this section demonstrates a range of values, or capital according to Bourdieu, which signify that it would be unwise to advocate a simplistic assumption of a rigid set of shared dispositions in a field. The participant though steeped in the habitus that inclines him towards one way of acting, thinking, believing (Bourdieu, 1990) over others, this does not preclude demonstrating an understanding that there are alternative ways of planning for the future.

PL Best case scenario would probably be still playing here, I've got, I'd love to be, I'd love to be here in five years' time and I'd love to be in the top, like in the top four teams in super league and I'd love to have won some sort of silverware, and from a personal point of view I'd love to have some sort of education behind me and stuff like that, like to have a degree and whatever, whatever tickles my fancy at the time 
It may be that the research situation itself calls for an idealised future plan, that said, how this is crafted for the response to the interviewer is interesting as it renders visible how success is understood by this member of this field. Furthermore, when it comes to showing an appreciation that perhaps some preparation for a career beyond playing rugby successfully is advisable the account becomes vague, imprecise, beyond the individual's control and subject to being something he 'fancies' doing. It could be that, so far, past experience and immersion in the current field do not provide any real, concrete, possible alternatives for the future.

To summarise this section of analysis, habitus appears to operate here as an organising principle and demonstrates how a professional sports person's world is assembled according to its own relevant logics. It appears that, while steeped within this world, performing successfully, there are few resources being drawn on to imagine or craft a life beyond it. The role of the organization, or institution, in legitimizing this dominant perspective is uncertain but may warrant future study.

The intention here is to illuminate these dominant logics of social action, so taken-for-granted they are no longer visible as a choice, which will enable an exploration and, to some extent, an explanation of the workings of this particular occupation. The body-damaging career may be regarded by some as ill-advised due to its temporary nature with potential for long-term ill-effects. However, there is no claim to demonstrate that this is in any way a stigmatised profession, or dirty work, instead the participants have accrued embodied capital in order to transgress from one field to another, more preferable, one. The ultimate bodily sacrifice that is required is taken as a disciplined route to better performance and is not questioned. The participants in the study, at the time of the study, have provided a normative framework to 'explain' their choice of this career which is unlikely to be questioned as either not true or not sensible. 


\subsection{Post sport careers}

According to Bourdieu (1977) a social field is a patterned set of practices within a broader social space. Although it has been argued that young, working class, men with few qualifications (and thus limited alternatives) are more likely to orient towards the body as a tool of employment (Nixon, 2009), this working environment requires exceptional levels of physical ability. In professional rugby, which is an intensely physical game, the player enters a 'body centred universe' (Wacquant, 1995a, p. 66) which requires field-appropriate capital to be deployed according to rules of the field. Despite all best efforts, the body will succumb to injury, wear and tear and an ageing process that renders the player unable to compete with younger, faster, stronger, bodies. Nevertheless, the rugby players are willing to sacrifice their carefully crafted and honed physical well-being to a body-damaging performance on the pitch without question.

In an environment where it is well understood that the playing career is short and likely to be curtailed through injury, how do the players talk about preparing for a life beyond the game? McGillivray et al., (2005, p. 64) carried out a study of Scottish footballers, in which their participants talked of working to be a personal trainer. They argued that this retained the utility of physical capital and maximised 'physical literacy' developed during the sports career. This view is also demonstrated in the extracts below.

PJ I wanted to be a PE teacher which is still something I'd probably like to fall back on when I finish playing.

P6 I wouldn't mind going into coaching really but I'm not sure, I haven't really thought about that, route yet but I've had, my old, school teacher phoned me up and he's asked me to do a course at university to work with naughty kids at school. 
Other accounts of remaining connected to sport were evident. However, in the following extract the player alludes to a transitionary strategy by talking about having to reduce the level of club he will be playing for as he gets older, signalling a need to stay connected with the sport for as long as possible. This resonates with some findings from Wainwright and Turner (2006) where an injured prima ballet dancer offered to dance in the chorus when her performance level dropped.

P4 it might be a case of I need to maybe drop down a level to Northern Ford (a lower level in the league) or it might be a case of right, you know, move on, retire and see where I go from here.

We can never ascertain what the participants would have done if they had not become successful at playing rugby, so alternatives remain unknown. It has been argued that working class men do not attain high levels of academic success typically and do relatively poorly at school (e.g. Nixon, 2009), thus a strong argument cannot be made that they have sacrificed academic achievement for the sport. It may be that they were alienated by education and found school difficult. However, in keeping with other studies of sports' professionals (McGillivray et al., 2005; Price, 2007) the rugby players do seem to have side-lined academic potential in favour of immersion in a dream of professional sport careers, referred to below in one retrospective accounting.

PI I probably would have, if I knew back then I would have put my head down at school and worked a bit harder and tried to get some skills to sort of get a real job I guess, but like, my favourite, my best skill was rugby league so I put all my effort into that.....if I did it again I'd definitely work harder at school.

In professional sports the future labour market is identified at an early age. Football clubs, for example, promote a set of dispositions towards football participation which devalues formal educational attainment in favour of the game (McGillivray et al., 2005, p. 106). In a similar way further education is likely to be sacrificed, or at least not focussed upon, based on the prospect of making it as a professional rugby player (even though it is well documented that 
playing careers are short and salaries are capped). Furthermore, it is commonly understood that successful ex-players go on to other careers which contrast starkly with the playing success that they have enjoyed. A participant demonstrates their understanding of this in the extract below.

P3 I've heard of in the past very successful professional rugby league players having amazing careers and then, you know, not saying it's a bad thing but end up being like a taxi driver.

That said, possibly pre-empted through involvement with the research and the research interview specifically, there are moments of clarity, or dawning realisation, that there are material consequences to this current total immersion in sport to the exclusion of giving some consideration for future careers. Even if it is through considering someone else's situation as in the following extract.

P6 I think if you ask most rugby players of my age now, twenty five, who've probably got five, six years left, seven years at most, I bet if you ask half of them at twenty five years old, they won't know what they, what they want to do after, because I've, it's only just really dawned on me now because like (ex-player) and he's thirty two and he did his A Levels but he didn't really, he didn't finish them because he started playing first team rugby.

When asked to consider what they might do having retired from the game, most of the players provided quite vague descriptions of what they may do. They featured idealised, nondetailed, accounts of what might be possible. This simply may reflect an inability to consider future selves beyond playing rugby - but that is precisely what Bourdieu alludes to in a dispositional habitus. In keeping with a recent study of indigenous Australian boxers, the authors argued that the athletes' life world was dominated by the field, without realistic alternatives while within the confines of their habitus. 'Boxing recruits, grooms and exploits young men, athletically, educationally and financially at the risk of being discarded once 
physical assets have eroded without adequate preparation to enter alternative occupations’ (Stronach and Adair, 2010, p. 67).

Thus, it is apparent that, within the field of professional sports there are few resources which are either prevalent or encouraged to be focussed on in too much detail for a life beyond playing. It could be that it is not in the Club's interest to be preparing the players for exit, but there is no claim that they are not willing participants in their current complete immersion in the field. The argument here is that the habitus of this work environment provides a template to not plan for a career beyond playing. Normative expectations and assumptions appear to be around focused commitment to the club and to their playing career, planning for exit suggests reduced commitment to the current focus.

And the final extract demonstrates a realisation, a coming full-circle, to repeat generational patterns of employment following the brief sojourn into professional rugby. This is a demonstrable understanding of the participant's brief escape from a working class habitus and his inevitable return.

PH My family's trade's like a plasterer and my Dad was a plasterer and my Granddad was a plasterer and when I wasn't full-time that's what I was doing, but I always hated it because I wanted to be a professional rugby player so I always felt that was holding me back from doing, like being professional rugby player, so I took a year out from that, you know, and just went without the money and, it improved me, do you know? I went and did my own training in the day because I wasn't full-time and then the year after I finally signed full-time, so, I'd probably end up being a plasterer but hating it, like my Dad does.

The above extract is illustrative of a player's perception that there are few alternative opportunities for meaningful employment which are local to the club in the study. It is quite understandable that a professional sports career is regarded as an opportunity to craft something special in terms of employment, albeit a potentially body damaging, temporally reduced, career. That said, and although there are well-known examples of drinking, 
gambling, relationship problems and, at the extreme, suicide attempts by some professional rugby players after they finish playing professionally; it would be too simplistic, and it is not an intention, to portray rugby league players too much as victims. It may rather be that an, albeit happy, escape to an alternative rugby-playing field simply does not provide a habitus or capitals for what to do next.

\section{Discussion}

In the paper it has been demonstrated how it is possible to render ordinarily invisible careerrelevant logics more visible utilising Bourdieu. The research provides a contrast to Hall's (2004) protean career theory which describes a career as managed by the individual according to their own values. It is not so much that the participants in the study are duped against their will to continue with this body-damaging career, rather they willingly acquiesce. What they produce for the research interaction is an account of naturalising, an account of lack of agency, it could be argued, both to explain entry to the sport and to demonstrate commitment (through not talking about preparing for retirement). Thus, the strong selfidentification of the self as athlete (Baillie, 1993) is invoked with the associated material consequences of not considering alternative (eventual) career options (Blann, 1985). This is not to suggest that these orientations to work come from the field of professional rugby league, individuals arrive with ready formed dispositions from earlier experiences. What the context provides, in terms of career-relevance are resources (or lack of), or logics, that deem what is appropriate for members of the organization to talk and think about, which includes post-playing career planning. This is in keeping with studies of athletes where the socialization process has evoked a strong athletic identity resulting in failure to explore alternative roles and thus risk career adjustment difficulties (Baillie, 1993).

Protean career theory should readily lend itself to a better understanding of this precarious, fragile, fractured, temporary career-world where planning for the future (even to the next 
game) is not possible. However, what we see is an articulation of agency as a shared disposition towards an embodied career which renders the players as largely unaware of, unprepared for, and removed from the possibilities of pursuing career pathways beyond those that deploy their physical literacy. This is not to argue that there is conscious discussion and agreement necessarily among the sports people, in fact it may be that these natural events are so long sedimented that they are no longer noticed.

As evident in the beginnings section of the analysis, entry to this field may be retrospectively constructed as almost accidental and beyond the control of the player (compelled to do it). This is an interesting account of agency as career theorists may expect to see a more sophisticated description of choice and entry to an elite (by contrast to alternative spheres of work locally available to the players) field of employment. It supports similar findings from other studies of working class attitudes to career choice (Artaraz, 2006; Colley, 2003; Willis, 1977), but differs in that sport has offered a temporary transcendence, or elevation, to this group of men. It is argued, therefore, that in this instance claiming the career choice in this way for them is a reproduction of the 'natural' order of things (it is a family tradition), somehow innate and uncontrollable (it's in my blood) and therefore demonstrates the relationship between a social way of being and choice (Vilhjálmsdóttir and Arnkelsson, 2013). Hence, a research perspective which pays attention to what discursive, or narrative, resources are drawn on to account for career choice, retrospectively and predictively offers insight to career theorists who need to understand the relationship between social structure and career choice.

With regard to extrapolating the relevance of the study of career-talk in the sport-as-work domain in order to understand career logics in other occupations, it is argued that these embodied careers are indicative of some current and possible future career-concerns in other contexts of work. First, in a broad sense, increased attention is being given to the role of 
judgements around age and ageing (as visible in embodied performances and assumed through stereotypically understood proxies for cognitive ability) in the work environment. It may be that an unintended consequence of recent UK legislation around age discrimination is that how we look, including; gait, posture, demeanour etc. have attained greater significance as career judgements are made. We are all subject, to greater or lesser degrees, to a valuejudgement based upon our embodied, occupationally relevant, performance according to the mores of our own fields of play. More explicitly though, other embodied work such as dancing and, possibly, acting, where increasing age signals a deterioration in the required bodily capital that would oblige the participants to seek lower grades of work until the body ‘just crumbles to bits’ (Wainwright and Turner, 2006, p. 237) demonstrate clear parallels with the study. It can be the concern of future research, to what extent physical 'literacy' impacts upon career choices.

Bourdieu's theory of practice has been drawn upon in the study as an overarching theory which has provided a framework to regard the individual as located socially with experiences. These work to provide identity resources for constructing more or less coherent narratives of a meaningful life. In the context of the study envisioning future selves and future choices appear to be difficult, if not impossible in any structured way, despite the inevitability of the forthcoming end to their playing careers. Thus individuals construct boundaries which locate them in the high-performing present with a disinclination to prepare for the future. The participants can be seen to be both consumers and producers of embodied social practices as they strive to stay fit-for-work in order to be picked for play each week for as long as possible. As each member of an organization brings a habitus formed under specific past conditions, paying attention to the role of habitus in organizations can therefore shed light on how structures are built from micro processes of individual behaviour. This has potential implications for new career theories. However, there is much debate around to what extent 
habitus reproduces social order on the one hand and how it may be a useful concept for opening up possibilities for theorizing change as an alternative view (McLeod, 2005). There have been criticisms of Bourdieu's concepts as vague and simply replicative of social structures (e.g. Jenkins, 1991) however, as a resource for social inquiry they offer potential to illuminate the varieties of logics of social action which may be operating in a social context. In a physically-taxing, embodied, occupation it is important to understand that the sedimented products of past social activities are carried within an associated embodied approach to work, thus the body operates as a target and receptacle of asymmetric power relations (Wacquant, 1995a). However, within the habitus of the study, control and ultimately damage of bodies by others is not resisted or subverted or even cynically disregarded, as may be the case in other work occupations. It may be argued that articulated resistance may develop as performance fades but they still perform according to required demands in order to keep performing for as long as possible.

In terms of contributing to the further development of work career theory, the theory of practice cannot easily offer operationalized empirical variables with immediate use for concrete empirical research designs. Rather, it proposes theoretical constructs which enable an examination of individuals in social spaces as both producers and consumers of social order through their career talk. Specifically in this empirical illustration; logics around bodydamaging work are ordinarily invisible and thus not questioned by the sports people, even though the damaged body renders future career pathways unsustainable and physical literacy is regarded as the only or at least the most important form of literacy in the sport world, to the detriment of possible alternatives.

\section{Conclusions}

It is clear that the study of professional rugby players' talk of their career progression beyond their elite position enables an understanding of how the context of their career-talk shapes its 
nature. The picture that is evoked is of an individual acting 'intentionally without intention' and offers insight for career theorists who place much weight on an individual's ability to choose. A critical awareness of social structures and habitus provides a view on the functioning of social variables, not as additions to psychological variables, but as in interaction with and potentially constructive of the individual's ability to 'choose'.

With regard to uncovering ordinarily invisible logics which operate in work contexts, and specifically sport contexts, the paper contributes in two important ways. First, the material and political consequences for the individual ending an elite sports career are not ordinarily considered. Once the playing career has ended and physical assets have eroded they are, in the main, discarded by the organizations that profit from their endeavour (professional sports clubs, media organizations, sponsoring organizations). The presumed logic that this is 'good' for the individuals who willingly acquiesce and enjoy a temporary period of high status masks the responsibility of the academic sports institutions and employing organisations to prepare sports people for future careers beyond playing. It is perhaps timely to begin to unravel the logic of this assumption.

The study also demonstrates a shared but negotiated system of meaning around another form of literacy - that of physical literacy. From an academic perspective, which places academic literacy as the only (or at least, the best) form of literacy, academic and specifically career theorists' understanding should be open to other forms of value which operate in other people's lives. Finally, the study draws attention to the embodied career, a strong argument for future research to re-consider the neglect of the working body and the bodily incorporation of social location and the mores of that field.

\section{References}

Artaraz, K. (2006). The wrong person for the job? Professional habitus and working cultures in 
Connexions. Critical Social Policy, 26, 910-931.

Arthur, M.B. \& Rousseau, D.M. (1996). (Eds.) The Boundaryless career: A new employment principle for a new organizational era. New York: Oxford University Press.

Baillie, P.H.F. (1993). Understanding retirement from sports. The Counselling Psychologist 21(3), 399-410.

Blann, F.W. (1985). Intercollegiate athletic competition and students' educational and career plans. Journal of College Student Personnel 26, 115-116.

Bourdieu, P. (1977). Outline of a theory of practice. Cambridge: Cambridge University Press. Bourdieu, P. (1990). The logic of practice. (R. Nice, Trans.) Cambridge: Polity Press.

Chudzikowski, K. \& Mayrhofer, W. (2011). In search of the blue flower? Grand social theories and career research: The case of Bourdieu's theory of practice. Human Relations 64(1), 19-36. Cohen, L. \& Mallon, M. (1999). The Transition from Organizational Employment to Portfolio Working: Perceptions of `Boundarylessness'. Work Employment and Society 13(2), 329-352.

Colley, H. (2003). Engagement mentoring for socially excluded youth: Problematic and holistic approach to creating employability through the transformation of habitus. British Journal of Guidance and Counselling, 31, 77-99.

Crossley, N. (2001). The social body: Habit, identity and desire. London: Sage.

Day, D.V., Gordon, S. \& Fink, C. (2012) The sporting life: exploring organizations through the lens of sport. Academy of Management Annals 6(1), 397-433.

DeFillipi, R.J. \& Arthur, M.B. (1996). Boundaryless careers and contexts: A competency based perspective. In M.B. Arthur and D.M. Rousseau (Eds.) The Boundaryless Career. New York: Oxford University Press, 116-131.

Gati, I. (1986). Making career decisions- a sequential elimination approach. Journal of Counseling Psychology 33, 408-417.

Goldschmidt, W. (1990). The Human career: The self in the symbolic world. Cambridge MA: 
Blackwell.

Grandjean, B.D. (1981). History and career in a bureaucratic labor market. The American Journal of Sociology 86(5), 1057-1092.

Guichard, J. (2009). Self-constructing. Journal of Vocational Behaviour, 75, 251-258.

Hall, D.T. (1996). Protean careers of the 21st century. Academy of Management Executive 10, 8-16.

Hall, D.T. (2004). The protean career: A quarter century journey. Journal of Vocational Behaviour, 65, 1-13.

Inkson, K., Gunz, H., Ganesh, S. \& Roper, J. (2012). Boundaryless careers: Bringing back boundaries. Organization Studies 33(3), 323-340.

Jenkins, R. (1991). Pierre Bourdieu. London: Routledge.

Lavallee, D. (2005). The effect of a life development intervention on sports career transition adjustment. The Sport Psychologist, 19(2), 193-202.

McGillivray, D., Fearn, R. \& McIntosh, A. (2005). Caught up in and by the beautiful game. Journal of Sport and Social Issues 29(1), 102-123.

McLeod, J. (2005). Feminists re-reading Bourdieu: Old debates and new questions about gender habitus and gender change. Theory and Research in Education 3(1), 11-30.

Nixon, D. (2009). 'I Can't Put a Smiley Face On’: Working-Class Masculinity, Emotional Labour and Service Work in the 'New Economy'. Gender, Work \& Organization, 16(3), 300322.

Ozbilgin, M. \& Tatli, A. (2005). Understanding Bourdieu's contribution to organization and management studies. Academy of Management Review, 30(4), 855-877.

Price, N. (2007). Game of two halves: Preparing young elite rugby players for a future beyond the game. Unpublished PhD thesis. Wollongon: University of Wollongong.

Pringle, J.K. \& Mallon, M. (2003). Challenges for the boundaryless career odyssey. 
International Journal of Human Resource Management, 14(5), 839-853.

Pringle, R. (2001). Competing discourses: Narratives of a fragmented self, manliness and rugby union. International Review for the Sociology of Sport, 36(4), 425-439.

Roderick, M. (2014). From identification to dis-identification: Case studies of job loss in professional football. Qualitative Research in Sport, Exercise and Health, 6(2), 143-160.

Savickas, M.L. (2006). Career construction theory. In Greenhaus JH \& Callaghan DG (Eds.) Encyclopaedia of Career Development. Thousand Oaks, CA: Sage, 85-89.

Stronach, M. \& Adair, D. (2010). Lords of the square ring: Future capital and career transition issues for elite indigenous Australian boxers. Cosmopolitan Civil Societies Journal, 2(2), 46-70. Sullivan, S.E. (1999). The changing nature of careers: A review and research agenda. Journal of Management, 25, 457-484.

Sullivan, S.E. \& Arthur, M. (2006). the evolution of the boundaryless career concept: Examining physical and psychological mobility. Journal of Vocational Behaviour, 69, 19-29. Super, D.E. (1990). A life span, life space approach to careers. Journal of Vocational Behaviour, 16, 282-298.

Van Maanen, J. (2011). Tales of the field: On writing ethnography $2^{\text {nd }}$ edition. London: University of Chicago Press.

Van Maanen, J. (2015). The present of things past: Ethnography and career studies Human Relations 68(1), 35-53.

Vilhjálmsdóttir, G. \& Arnkelsson, G.B. (2013). Social aspects of career choice from the perspective of habitus theory. Journal of Vocational Behaviour, 83, 581-590.

Wacquant, L. (1995a). Pugs at work: Bodily capital and bodily labour among professional boxers. Body and Society, 1(1), 65-93.

Wacquant, L. (1995b). The pugilistic point of view: How boxers think and feel about their trade. Theory and Society, 24, 489-535. 
Wainwright, S. \& Turner, B. (2006). Just crumbling to bits? An exploration of the body, ageing, injury and career in classical ballet dancers. Sociology, 40(2), 237-255.

Willis, P. (1977). Learning to labour: How working class kids get working class jobs. London: Hutchinson.

\section{Appendix}

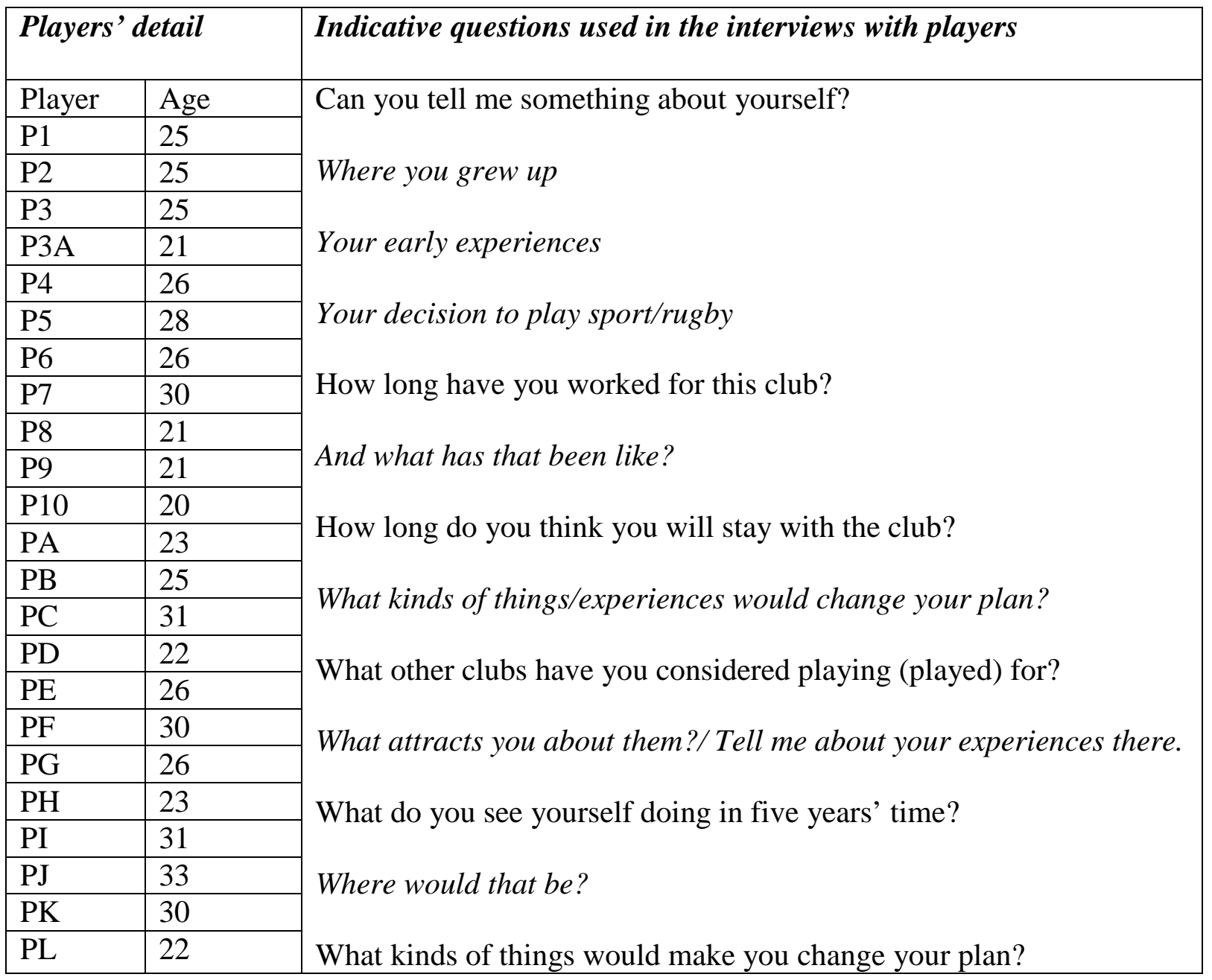

